ESAIM: PROCEEDINGS, October 2007, Vol. 22, 140-149

Gabriel Caloz \& Monique Dauge, Editors

\title{
TWINES EQUILIBRIUM IN A FINITE ELEMENT DEDICATED TO HEXAGONAL MESH NETTING
}

\author{
DANIEL PRIOUR ${ }^{1}$
}

\begin{abstract}
The equilibrium of hexagonal mesh netting is calculated by a finite element method. A triangular element has been devolopped for such hexagonal meshes [1] [2]. The hexagonal mesh is made of three families of twines. The basic hypothesis of the triangular element imposes that the three families of twines be parallel inside the element. The twine tension are calculated to deduce the forces on the vertex of the triangular element.

The calculation of twine tension needs the concurent resolution of 6 equations with as many unknowns. In a first step these equations are reduced to 2 with 2 unknowns. Then they are solved by the Newton-Raphson method.

Résumé. L'équilibre de filets à mailles hexagonales est calculé par une méthode aux éléments finis. Pour cela un élément fini triangulaire dédié au filet à maille hexagonale a été développé [1] [2]. La maille hexagonale est constituée de trois familles de fils. L'hypothèse de base de l'élément triangulaire impose que les trois familles de fils soient parallèles à l'intérieur de l'élément. Les tensions dans les fils sont calculées pour en déduire les efforts aux sommets de l'élément triangulaire.

Le calcul des tensions de fils implique la résolution simultanée de 6 équations à autant d'inconnues. Dans un premier temps ces équations sont réduites à 2 équations à 2 inconnues. Ensuite celles-ci sont résolues par la méthode de Newton-Raphson.
\end{abstract}

\section{INTRODUCTION}

Netting structures could be ranked in 3 classes related to the mesh shape: diamond mesh, square mesh and hexagonal mesh (fig.1). From mechanical modeling point of view they are ranked in only 2 famillies: the meshes with 2 twine directions (diamond and square) and 3 directions (hexagonal).

\footnotetext{
${ }^{1}$ IFREMER, STH/LTH, BP 70, pointe du diable, 29280 Plouzané, daniel.priour@ifremer.fr
} 

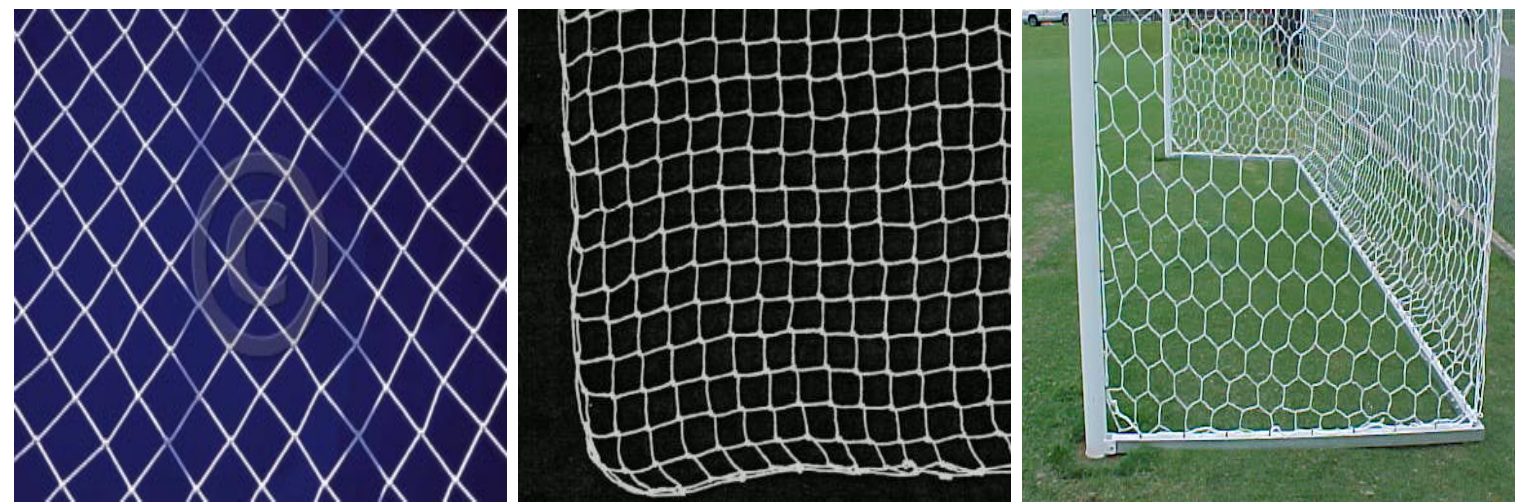

Figure 1: Nettings with diamond, square and hexagonal meshes

Most of netting modellings have been devoted to the first family (2 directions of twine) [3-9]. For the second family (3 directions of twine)only few works have been completed $[1,5]$.

Recently, the use of netting in a given direction has been imposed for specific fishery improvements: The netting is generally towed along the $\mathrm{N}$ direction (horizontal on fig.2), but a recent regulation imposes to tow the netting in the $\mathrm{T}$ direction (vertical on fig.2). Thus the modelling must be able to embed this modification. Two cases are considered: either the mesh twines are assumed to have two directions, which means that the knot effect must be taken into account, for example by a mesh opening stiffness [10-12], or the mesh is assumed to be hexagonal [1].

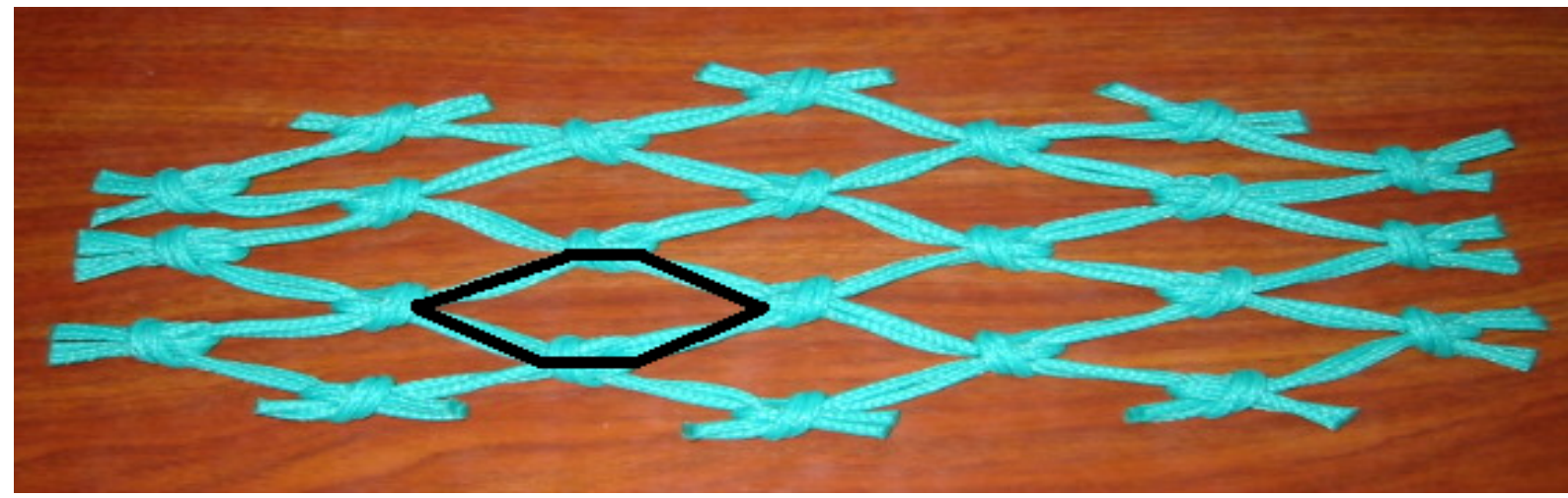

Figure 2: Netting with large knot. The $\mathrm{N}$ direction is horizontal and the $\mathrm{T}$ one is vertical. This mesh can be assimilated to a hexagonal one: the knot would be one side of the hexagon.

In this paper the modelling of hexagonal mesh netting by finite element method is studied [1]. The present paper focuses on the equilibrium of twines inside the finite element dedicated to hexagonal mesh netting.

\section{Method}

\subsection{Sides of the basic mesh}

The modelling is based on a triangular finite element. The netting can be assimilated to a surface, thus the triangle has been chosen for being the simplest shape of surface. 


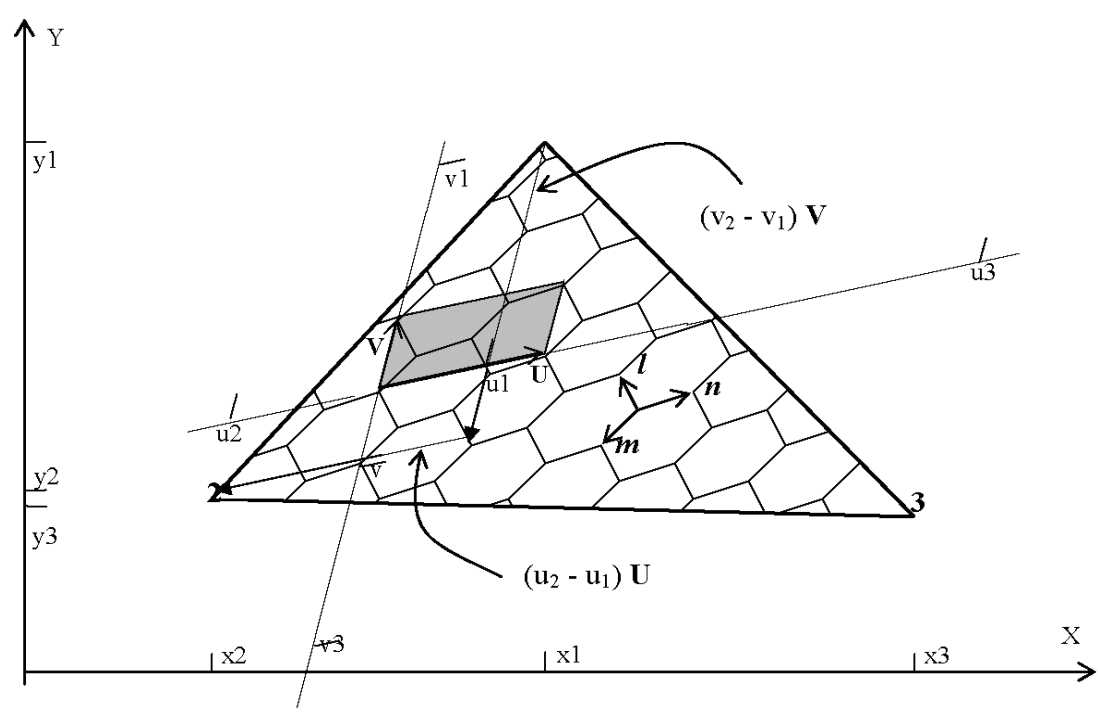

Figure 3: Triangular element dedicated to hexagonal mesh netting. Twine directions are $\mathrm{l}, \mathrm{m}$ and $\mathrm{n}$. Cartesians coordinates are $x_{1}, y_{1}, x_{2}, y_{2}, x_{3}$ and $y_{3}$. Twine coordinates are $u_{1}, v_{1}, u_{2}, v_{2}, u_{3}$ and $v_{3}$. The basic mesh is in grey and is defined by vectors $\boldsymbol{U}$ and $\boldsymbol{V}$.

The whole netting is modelled in triangular elements, each of them able to cover a large number of twines. Each vertex, or node, is linked to the netting, so when the modelling calculates the equilibrium of nodes the equilibrium of the netting is known.

The basic hypothesis is that each familly of twine in a triangular element stays parallel, i.e. all the l twines are parallel, the same for $\mathrm{m}$ and $\mathrm{n}$ twines. It is clear that this leads to a constant deformation per family. Obsviously both the orientation and deformation of twines vary from one triangular element to another. This hypothesis is acceptable if the triangular elements are small enough relatively to the gradient of deformation.

A second hypothesis is that the twines are modelled as elastic bars with different moduli of Young to take into account twine tension and compression. This hypothesis is acceptable because the twine strain being pretty small (few percents).

From these hypothesis the twine tensions will be calculated and therefore the forces exerted on the nodes.

In each triangular element the netting can be described by a juxtaposition of "basic meshes". This basic mesh is in grey on fig. 3 and fig.4. Such basic mesh is made of 6 twines: $21,2 \mathrm{~m}$ and $2 \mathrm{n}$. The basic mesh is a parallelogram which sides are vectors $\boldsymbol{U}$ and $\boldsymbol{V}$. These vectors $\boldsymbol{U}$ and $\boldsymbol{V}$ are used to define the twine coordinates of nodes (fig.3 and 4). 

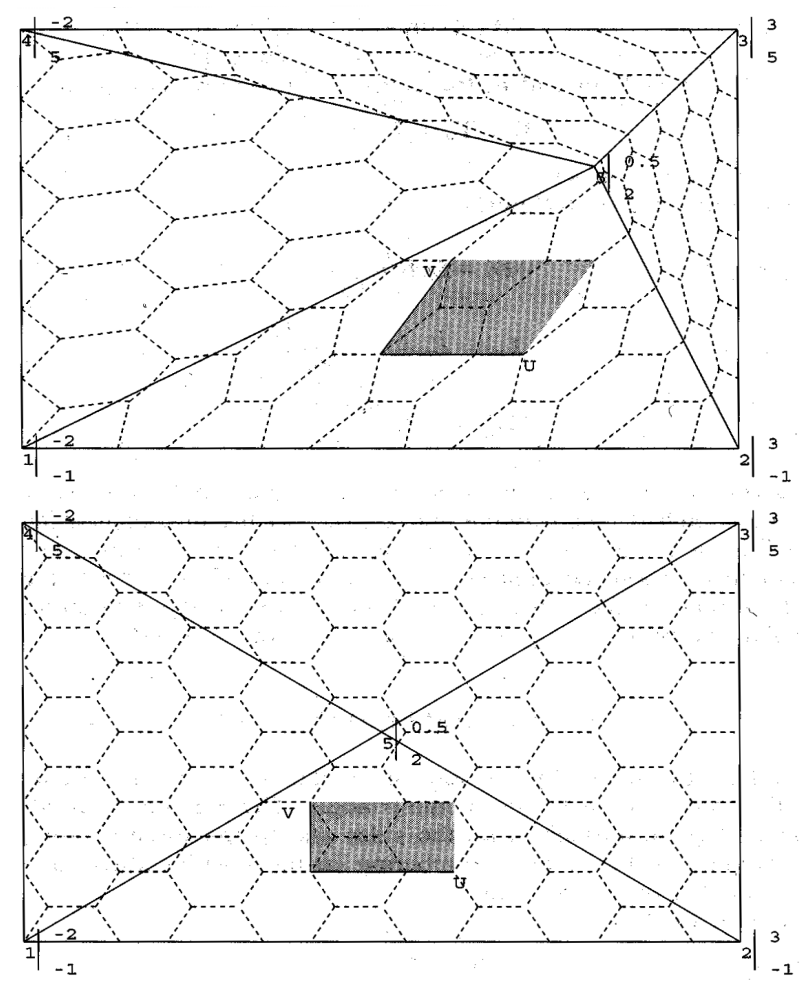

Figure 4: Equilibrium calculation of a netting (dotted lines) stretched at each four sides. 4 triangular elements are used (solid lines). The initial shape (not equilibrated) is the top one. The final shape (equilibrated) is the bottom one. The twine coordinates of the 5 nodes are marked. The basic mesh of the bottom triangle is in grey.

Due to the linear combinations between basic mesh sides and triangle sides, the sides of the basic mesh are calculated from the sides of each triangular element, with the following equations (fig.3):

$\mathbf{1 2}=\left(u_{2}-u_{1}\right) \boldsymbol{U}+\left(v_{2}-v_{1}\right) \boldsymbol{V}$

$\mathbf{1 3}=\left(u_{3}-u_{1}\right) \boldsymbol{U}+\left(v_{3}-v_{1}\right) \boldsymbol{V}$

$u_{1}, u_{2}, u_{3}$ are the twine coordinates along $\boldsymbol{U}$ vector of vertex 1,2 and 3 of the triangle. The same along $\boldsymbol{V}$ vector.

From these 2 equations with 2 unknowns, $\boldsymbol{U}$ and $\boldsymbol{V}$ can be deduced:

$U=\frac{v_{3}-v_{1}}{d} 12-\frac{v_{2}-v_{1}}{d} 13$

$V=\frac{u_{3}-u_{1}}{d} 12-\frac{u_{2}-u_{1}}{d} 13$

with

$d=\left(u_{2}-u_{1}\right)\left(v_{3}-v_{1}\right)-\left(u_{3}-u_{1}\right)\left(v_{2}-v_{1}\right)$

In fact the number of basic meshes is equal to $\frac{d}{2}$, i.e. the number of 1 twines is $d$, the same for the number of $\mathrm{m}$ and $\mathrm{n}$ twines. Obviously the total number of twines in the triangular element is $3 \mathrm{~d}$. 


\subsection{Twines tension}

The basic mesh definition leads to (fig.3):

$U=-\boldsymbol{m}+2 \boldsymbol{n}-\boldsymbol{l}$

$V=-m+l$

The tension amplitudes are:

$$
\begin{aligned}
& \left|\boldsymbol{T}_{\boldsymbol{l}}\right|=E A \frac{|\boldsymbol{l}|-l_{o}}{l_{o}} \\
& \left|\boldsymbol{T}_{\boldsymbol{m}}\right|=E A \frac{|\boldsymbol{m}|-m_{o}}{m_{o}} \\
& \left|\boldsymbol{T}_{\boldsymbol{n}}\right|=E A \frac{|\boldsymbol{n}|-n_{o}}{n_{o}}
\end{aligned}
$$

With $E$ the young modulus of twine.

And $A$ the section of twine.

The equilibrium of twine tension gives:

$T_{l}+T_{m}+T_{n}=0$

Which gives 6 equations with 6 unknowns $\left(\boldsymbol{l}, \boldsymbol{m}, \boldsymbol{n}, \boldsymbol{T}_{\boldsymbol{l}}, \boldsymbol{T}_{\boldsymbol{m}}\right.$ and $\left.\boldsymbol{T}_{\boldsymbol{n}}\right)$.

\subsection{Equilibrium of the joint knot}

The 6 previous equations can be reduced to the two following with two unknowns $\left(m_{x}\right.$ and $\left.m_{y}\right)$ :

$$
\begin{aligned}
& \frac{\left(m_{x}+V_{x}\right)\left(\sqrt{\left(m_{x}+V_{x}\right)^{2}+\left(m_{y}+V_{y}\right)^{2}}-l_{o}\right)}{l_{o} \sqrt{\left(m_{x}+V_{x}\right)^{2}+\left(m_{y}+V_{y}\right)^{2}}}+\frac{\left(m_{x}\right)\left(\sqrt{m_{x}^{2}+m_{y}^{2}}-m_{o}\right)}{m_{o} \sqrt{m_{x}^{2}+m_{y}^{2}}}+\frac{\left.\left(m_{x}+\frac{U_{x}+V_{x}}{2}\right)\left(\sqrt{\left(m_{x}+\frac{U_{x}+V_{x}}{2}\right)^{2}+\left(m_{y}+\frac{U_{y}+V_{y}}{2}\right.}\right)^{2}-n_{o}\right)}{n_{o} \sqrt{\left(m_{x}+\frac{U_{x}+V_{x}}{2}\right)^{2}+\left(m_{y}+\frac{U_{y}+V_{y}}{2}\right)^{2}}}=0 \\
& \frac{\left(m_{y}+V_{y}\right)\left(\sqrt{\left(m_{x}+V_{x}\right)^{2}+\left(m_{y}+V_{y}\right)^{2}}-l_{o}\right)}{l_{o} \sqrt{\left(m_{x}+V_{x}\right)^{2}+\left(m_{y}+V_{y}\right)^{2}}}+\frac{\left(m_{y}\right)\left(\sqrt{m_{x}^{2}+m_{y}^{2}}-m_{o}\right)}{m_{o} \sqrt{m_{x}^{2}+m_{y}^{2}}}+\frac{\left.\left(m_{y}+\frac{U_{y}+V_{y}}{2}\right)\left(\sqrt{\left(m_{x}+\frac{U_{x}+V_{x}}{2}\right)^{2}+\left(m_{y}+\frac{U_{y}+V_{y}}{2}\right.}\right)^{2}-n_{o}\right)}{n_{o} \sqrt{\left(m_{x}+\frac{U_{x}+V_{x}}{2}\right)^{2}+\left(m_{y}+\frac{U_{y}+V_{y}}{2}\right)^{2}}}=0
\end{aligned}
$$

With $m_{x}\left(U_{x}, V_{x}\right)$ and $m_{y}\left(U_{y}, V_{y}\right)$ components of $\boldsymbol{m}(\boldsymbol{U}, \boldsymbol{V})$ :

These 2 equations are the complete form of the following:

$$
\begin{aligned}
& \frac{l_{x}}{|\boldsymbol{l}|} \frac{|\boldsymbol{l}|-l_{o}}{l_{o}}+\frac{m_{x}}{|\boldsymbol{m}|} \frac{|\boldsymbol{m}|-m_{o}}{m_{o}}+\frac{n_{x}}{|\boldsymbol{n}|} \frac{|\boldsymbol{n}|-n_{o}}{n_{o}}=0 \\
& \frac{l_{y}}{|\boldsymbol{l}|} \frac{|\boldsymbol{l}|-l_{o}}{l_{o}}+\frac{m_{y}}{|\boldsymbol{m}|} \frac{|\boldsymbol{m}|-m_{o}}{m_{o}}+\frac{n_{y}}{|\boldsymbol{n}|} \frac{|\boldsymbol{n}|-n_{o}}{n_{o}}=0
\end{aligned}
$$

These 2 equations describe the equilibrium of the joint knot of 3 twines in a triangle which sides are $\frac{U+\boldsymbol{V}}{2}$ and $\boldsymbol{V}$ (fig.5). These equations are in Newton. 


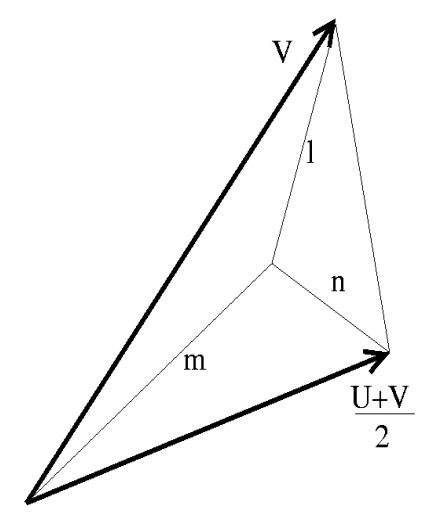

Figure 5: The 3 twines are in the triangle defined by $\frac{U+V}{2}$ and $\boldsymbol{V}$.

\subsection{Approximation of the equilibrium of the joint}

The analytical solution of the 2 previous equations has not been found, therefore the following approximation has been made in order to simplify the equations. This approximation is acceptable as the stretched twine lengths being close to the unstretched lengths.

$$
\begin{aligned}
& \frac{m_{x}}{\left|\boldsymbol{m}_{y}\right|} \approx \frac{m_{x}}{m_{o}} \\
& \frac{m_{y}}{|\boldsymbol{m}|} \approx \frac{m_{y}}{m_{o}}
\end{aligned}
$$

With this approximation the 2 previous equilibrium equations are reduced to the following:

$$
\begin{aligned}
& \left.\frac{\left(m_{x}+V_{x}\right)}{l_{o}^{2}}\left(\sqrt{\left(m_{x}+V_{x}\right)^{2}+\left(m_{y}+V_{y}\right)^{2}}-l_{o}\right)+\frac{m_{x}}{m_{o}^{2}}\left(\sqrt{m_{x}^{2}+m_{y}^{2}}-m_{o}\right)+\frac{\left(m_{x}+\frac{U_{x}+V_{x}}{2}\right.}{n_{o}^{2}}\right) \\
& \left.n_{o}\right)=0
\end{aligned}
$$

$\frac{\left(m_{y}+V_{y}\right)}{l_{o}^{2}}\left(\sqrt{\left(m_{x}+V_{x}\right)^{2}+\left(m_{y}+V_{y}\right)^{2}}-l_{o}\right)+\frac{m_{y}}{m_{o}^{2}}\left(\sqrt{m_{x}^{2}+m_{y}^{2}}-m_{o}\right)+\frac{\left(m_{y}+\frac{U_{y}+V_{y}}{n_{o}^{2}}\right)}{n_{o}^{2}}\left(\sqrt{\left(m_{x}+\frac{U_{x}+V_{x}}{2}\right)^{2}+\left(m_{y}+\frac{U_{y}+V_{y}}{2}\right)^{2}}-\right.$ $\left.n_{o}\right)=0$

Which is the complete form of the following:

$\frac{l_{x}}{l_{o}^{2}}\left(|\boldsymbol{l}|-l_{o}\right)+\frac{m_{x}}{m_{o}^{2}}\left(|\boldsymbol{m}|-m_{o}\right)+\frac{n_{x}}{n_{o}^{2}}\left(|\boldsymbol{n}|-n_{o}\right)=0$

$\frac{l_{y}}{l_{o}^{2}}\left(|\boldsymbol{l}|-l_{o}\right)+\frac{m_{y}}{m_{o}^{2}}\left(|\boldsymbol{m}|-m_{o}\right)+\frac{n_{y}}{n_{o}^{2}}\left(|\boldsymbol{n}|-n_{o}\right)=0$

\subsection{Newton-Raphson method}

The previous approximation has not been sufficient to reach the analytical solution. The Newton-Raphson method has been used to find a numerical solution. 
This method can be explained by the definition of the derivative of a function ( $\left.\mathrm{F}^{\prime}\right)$ :

$F^{\prime}=\frac{F(x+h)-F(x)}{h}$
$h \rightarrow 0$

$\mathrm{F}^{\prime}$ : derivative of the force $(\mathrm{N} / \mathrm{m})$.

$\mathrm{F}$ : force on the node $(\mathrm{N})$.

$\mathrm{x}$ : position of the node $(\mathrm{m})$.

$\mathrm{h}$ : displacement of the node $(\mathrm{m})$.

If $\mathrm{x}$ is not the equilibrium position, the displacement $\mathrm{h}$ is searched to found the equilibrium. Following this condition it can be written:

$F(x+h)=0$

Which gives with the definition of the derivative:

$h=\frac{F(x)}{-F^{\prime}(x)}$

Obviously, h can be large and $h \rightarrow 0$ is not respected. Thus the iterative calculation is required:

$h_{k+1}=\frac{F\left(x_{k}\right)}{-F^{\prime}\left(x_{k}\right)}$

$x_{k+1}=x_{k}+h_{k+1}$

$\mathrm{k}$ is the number of the iteration.

Here:

The derivative is:

$$
\begin{gathered}
\boldsymbol{F}=\left\{\begin{array}{l}
\frac{l_{x}}{l^{2}}\left(|\boldsymbol{l}|-l_{o}\right)+\frac{m_{x}}{m_{o}^{2}}\left(|\boldsymbol{m}|-m_{o}\right)+\frac{n_{x}}{n_{o}}\left(|\boldsymbol{n}|-n_{o}\right)=F_{1} \\
\frac{l_{y}^{\prime}}{l_{o}^{2}}\left(|\boldsymbol{l}|-l_{o}\right)+\frac{m_{y}^{2}}{m_{o}^{2}}\left(|\boldsymbol{m}|-m_{o}\right)+\frac{n_{y}}{n_{o}^{2}}\left(|\boldsymbol{n}|-n_{o}\right)=F_{2}
\end{array}\right. \\
\boldsymbol{x}=\left\{\begin{array}{l}
m_{x} \\
m_{y}
\end{array}\right.
\end{gathered}
$$

$$
F^{\prime}=\left|\begin{array}{cc}
-\left[\frac{\left(\boldsymbol{l}-l_{o}+\frac{l_{x}^{2}}{l}\right)}{l_{o}^{2}}+\frac{\left(\boldsymbol{m}-m_{o}+\frac{m_{x}^{2}}{m}\right)}{m_{o}^{2}}+\frac{\left(\boldsymbol{n}-n_{o}+\frac{n_{x}^{2}}{n}\right)}{n_{o}^{2}}\right] & -\left[\frac{l_{x} l_{y}}{l l_{o}^{2}}+\frac{m_{x} m_{y}}{\boldsymbol{m} m_{o}^{2}}+\frac{n_{x} n_{y}}{\boldsymbol{n} n_{o}^{2}}\right] \\
-\left[\frac{l_{x} l_{y}}{\boldsymbol{l} l_{o}^{2}}+\frac{m_{x} m_{y}}{\boldsymbol{m} m_{o}^{2}}+\frac{n_{x} n_{y}}{\boldsymbol{n} n_{o}^{2}}\right] & -\left[\frac{\left(\boldsymbol{l}-l_{o}+\frac{l_{y}^{2}}{\boldsymbol{l}}\right)}{l_{o}^{2}}+\frac{\left(\boldsymbol{m}-m_{o}+\frac{m_{y}^{2}}{\boldsymbol{m}}\right)}{m_{o}^{2}}+\frac{\left(\boldsymbol{n}-n_{o}+\frac{n_{y}^{2}}{\boldsymbol{n}}\right)}{n_{o}^{2}}\right]
\end{array}\right| .
$$

or

$$
F^{\prime}=\left|\begin{array}{ll}
D_{11} & D_{12} \\
D_{21} & D_{22}
\end{array}\right|
$$

With the previous conditions the displacement $(\boldsymbol{h})$ can be calculated:

$$
\boldsymbol{h}=\left\{\begin{array}{l}
\frac{D_{22} F_{1}-D_{12} F_{2}}{D_{\mathfrak{D}_{22}} D_{11}-D_{12} D_{21}} \\
\frac{D_{22} F_{2}-D_{21} F_{1}}{D_{22} D_{11}-D_{12} D_{21}}
\end{array}\right.
$$


From this displacement and with the iterative method previously described the equilibrium of the twines is calculated.

\subsection{Finite element method applied to hexagonal mesh netting}

Once the equilibrium of the twines is calculated, the finite element method dedicated to the netting can be implemented as described in [1].

\section{Applications}

\section{1. gabion}

Gabions are used in retention wall along roads or rivers. The following calculations (fig.6) were devoted to the assessment of the volume reduction of the gabion resulting from the high reduction of its height.
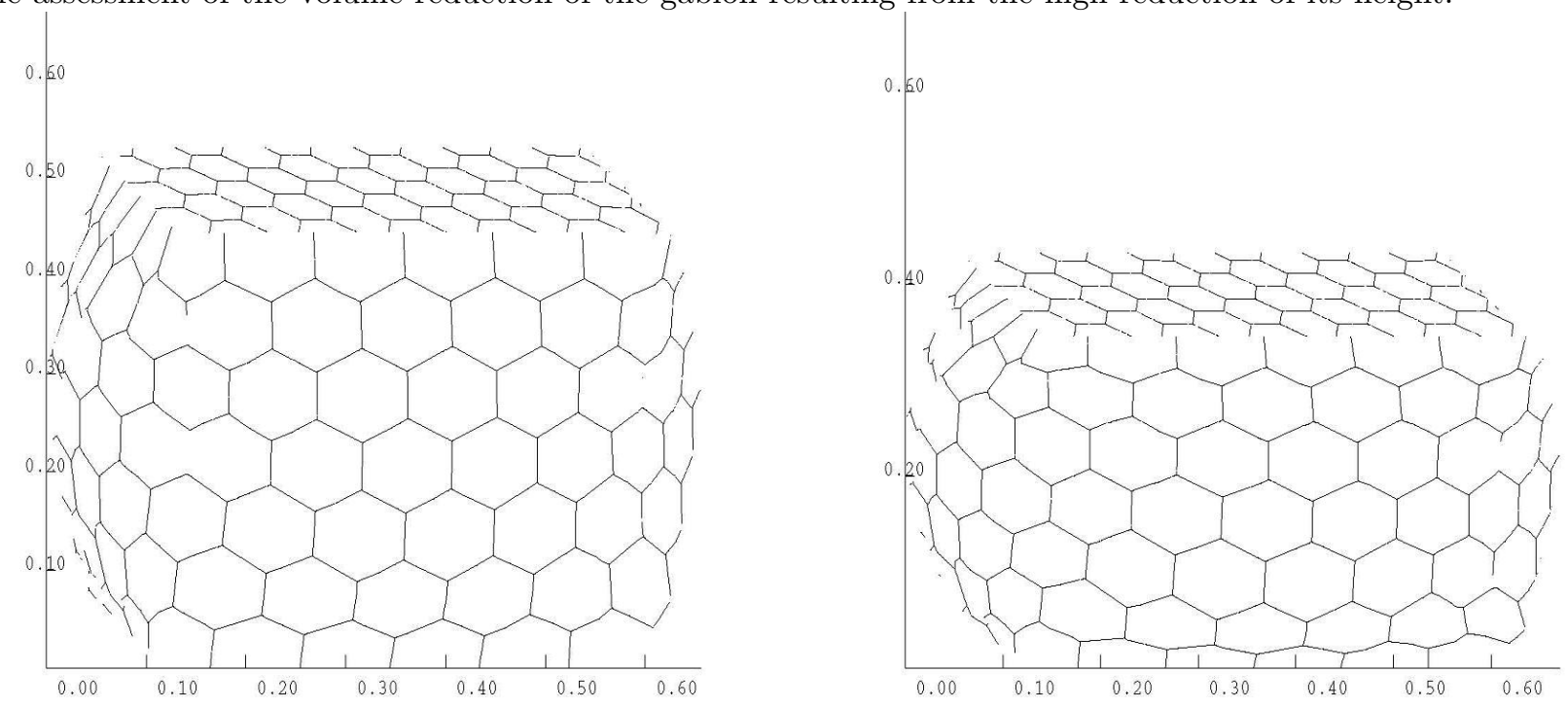

Figure 6: Calculation of gabion for 5 and 15 percent of height reduction (from left to right).

\section{2. cod-end}

Cod-ends are the rearmost part of trawls, they need investigation to assess their ability to retain or release fish. In this calculation the objective was to assess the cod-end shape variation between diamond meshes (fig.7 left) and hexagonal meshes (fig.7 right). This assessment is used to calculate the opening of meshes and therefore the escapement possibility of fish in relation to their size. 

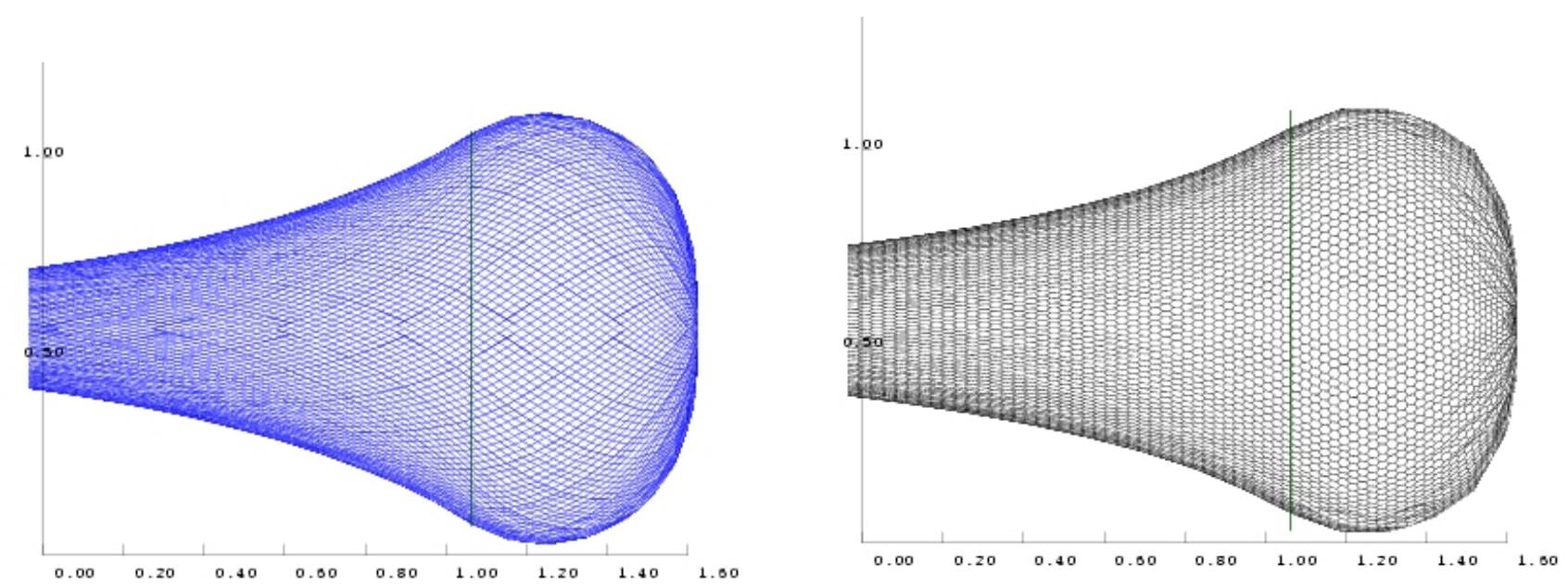

Figure 7: Cod-ends with diamond (left) and hexagonal meshes (right). The vertical line is the fish catch limit.

\section{Discussion}

The development of a triangular element dedicated to netting made of hexagonal meshes required to calculate the twine tension in the element. Unfortunately, the analytical solution of these tensions has not been found. Therefore an approximation has been carried out on the orientation of the twine tension and finally a numerical solution has been implemented based on the Newton-Raphson method.

The main advantage of such triangular element is that the discretisation of the whole netting is pretty easy.

Such development of numerical model devoted to hexagonal meshes could be used for the assessment of structures made of hexagonal meshes such as trawls cod-end for the assessment of the fishing process.

\section{REFERENCES}

[1] Priour D., Analysis of nets with hexagonal mesh using triangular element, Int. J. Numer. Meth. Engng, 56, p 1721-1733, 2003.

[2] Priour D., FEM modeling of flexible structures made of cables, bars and nets, Maritime Transportation and Exploitation of Ocean and Coastal Resources Guedes Soares, Garbatov and Fonseca (eds) Taylor and Francis Group, London, ISBN 0415 390362 Revue, p 1285-1292, 2005.

[3] Ferro RST., Computer simulation of trawl gear shape and loading, Proceedings of word symposium on fishing gear and fishing vessel design, p 259-262. 1988.

[4] Théret F., Étude de l'équilibre des surfaces réticulées placées dans un courant uniforme. Application aux chaluts, Thèse de doctorat de l'école centrale de Nantes et de l'université de Nantes. no ED 82-31. 1993.

[5] O'Neill FG., Differential equations governing the geometry of a diamond mesh cod-end of a trawl net, Journal of applied mechanics, Vol. 64/7, 453, p 1631-1648. March 1997.

[6] Priour D., Net shape calculation by finite element method, Workshop on fishing gears, Ifremer Lorient, 1-3 Oct. 1997.

[7] Niedzwiedz G., Model specification and further applications of the calculation of rope systems, contribution on the therory of fishing gears and related marine systems, V.2, IBSN 9-935319-88-6. 2001.

[8] Tsukrov I., Eroshkin O., Fredriksson D., Swift MR. and Celokkol B., Finite element modeling of net panels using a consistent net element, Ocean Engineering 30 p251-270. 2003.

[9] LeE CW., Computation modeling of the moored flexible structures, Maritime Transportation and Exploitation of Ocean and Coastal Resources Guedes Soares, Garbatov and Fonseca (eds) Taylor and Francis Group, London, ISBN 0415390362 Revue, p 1239-1243, 2005. 
[10] Herrmann B., Priour D. and Krag LA., Simulation based study of the combined effect on cod-end size selection of turning mesh orientation and of reducing the number of meshes in the circumference, Submitted to Fisheries research, 2006.

[11] O'Neill F.G., The influence of bending stiffness on the deformation of axisymmetric networks, Proceedings of OMAE'04, June 20-25, 2004, Vancouver Canada.

[12] Priour D., Introduction of mesh resistance to opening in a triangular element for calculation of nets by the finite element method, Commun. Numer. Meth. Engng, 17, p 229-237, 2001. 